\title{
SIM e SINASC: representação social de enfermeiros e profissionais de setores administrativos que atuam em hospitais no município de São Paulo
}

\author{
SIM and SINASC: social representation of nurses \\ and professional in administrative sectors who work \\ in hospitals in the city of São Paulo
}

\author{
Daniela Schoeps ${ }^{1}$ \\ Marcia Furquim de Almeida ${ }^{1}$ \\ Priscila Ribeiro Raspantini ${ }^{1}$ \\ Hillegonda Maria Dutilh Novaes ${ }^{1}$ \\ Zilda Pereira da Silva ${ }^{1}$ \\ Fernando Lefevre ${ }^{1}$
}

\begin{abstract}
Few studies have analyzed the SINASC (Live Birth Information System) and MIS (Mortality Information System) applying qualitative methodology seeking to understand data production processes and contexts. This article aims to study the social representation of health professionals about Live Birth Certificates (LBC) and perinatal Death Certificates (DC). A total of 24 interviews were conducted with nurses and otherprofessionals of 16 Unified Health System (SUS) and non-SUS hospitals of the city of São Paulo in 2009. Qualitative methodology was adopted along with the Collective Subject Discourse technique. Professionals acknowledged that they are an integral part of the information production process of SINASC and their reports indicate that they incorporate it in their work routine. They also perceive that training activities are a tool to understand the information produced by them and are aware of the utility of $L B C$ information. Although physicians are legally responsible for the $D C$, other professionals frequently provide some of the information to complete it. The professionals see themselves as participants of the SINASC. Despite providing information to complete the $D C$, they do not see themselves as participants of the MIS operation.
\end{abstract}

Keywords Mortality Information System, Live Birth Information System, Social representation, Quality of information
Resumo Poucos estudos analisaram o SINASC e SIM com metodologia qualitativa, visando compreender os processos e os contextos na produção dos dados. O objetivo deste artigo é estudar a representação social dos profissionais de saúde sobre as Declaração de Nascido Vivo (DN) e Declarações de Óbito (DO) perinatais. Foram realizadas 24 entrevistas com enfermeiros e outros profissionais em 16 hospitais, SUS e Não SUS, no município de São Paulo, em 2009. Foi utilizada metodologia qualitativa com a técnica do Discurso do Sujeito Coletivo. Os profissionais se reconhecem como parte integrante do processo de produção da informação do SINASC e os discursos indicam sua incorporação na rotina de trabalho, e percebem que o treinamento é um espaço de retorno, e a compreensão das informações que produzem e conhecem sobre a utilidade das informações registradas nas DN. Apesar do médico ser legalmente responsável pela DO, frequentemente outros profissionais preenchem parte das informações. Os profissionais se sentem participantes na operação do SINASC, porém apesar de preencherem informações da DO, estes não são incorporados e se percebem como integrantes da operação do SIM.

Palavras-chave Sistema de Informação de Mortalidade, Sistema de Informação de Nascidos Vivos, Representação social, Qualidade da informação
Universidade de São

Cerqueira Cesar.

01246-904 São Paulo SP. schoeps@usp.br 


\section{Introdução}

A mortalidade perinatal é um importante indicador de saúde materno-infantil. O interesse crescente por este indicador, e a consequente preocupação com a qualidade da informação, é decorrente da concentração progressiva dos óbitos infantis nos primeiros dias de vida, tanto em países desenvolvidos como em alguns em desenvolvimento, entre os quais o Brasil ${ }^{1,2}$. Observase evolução nos estudos de avaliação dos sistemas de informações perinatais. Inicialmente, esses estudos destinavam-se apenas à avaliação da completitude e cobertura dos dados, evoluindo para avaliação de sua acurácia, por meio da concordância dos registros com outras fontes de dados e, posteriormente, na década de 90 , surgiram estudos epidemiológicos de validação dos dados dos sistemas de informação de nascidos vivos $^{3}$. Nos anos 2000, ampliam-se as dimensões da qualidade investigadas, analisando-se aspectos combinados tais como: acessibilidade, clareza metodológica, coerência e não duplicidade ${ }^{4}$. Tais estudos têm se tornado cada vez mais importantes face à crescente disponibilidade de informações por meio eletrônico, e à maior incorporação da informática, que possibilita a ampliação do uso dessas informações ${ }^{3-7}$.

Estudos indicam que a definição clara do evento, juntamente com a definição das variáveis utilizadas para sua descrição, também desempenha importante papel na qualidade dos dados ${ }^{8}$. Segundo Arts et al. ${ }^{5}$, para assegurar a qualidade das informações é necessário garantir processos adequados na etapa anterior à coleta de dados, como a existência de protocolo de registro e coleta de dados com definições claras, treinamento e motivação dos profissionais responsáveis pelo preenchimento das informações. Fatores institucionais, como a estrutura, a organização e o tipo dos serviços de saúde podem influenciar a qualidade do registro de dados ${ }^{8}$.

Segundo as normas contidas no Manual de Preenchimento da Declaração de Nascido Vivo $(\mathrm{DN})$, estas podem ser preenchidas por médico, por membro da equipe de enfermagem da sala de parto ou do berçário, ou por outra pessoa previamente treinada para tal fim'. Embora raros, estudos buscaram identificar a relação entre a qualidade das informações e a rotina de preenchimento desses dados. Mishima et al. ${ }^{10}$ identificaram que o preenchimento da DN é heterogêneo nos hospitais. Em estudo específico sobre malformações congênitas das DN, Guerra et al. ${ }^{11}$ encontraram que diferentes profissionais preen- cheram as DN e nem sempre têm familiaridade com termos médicos do prontuário, o que pode interferir na qualidade dos dados. Niobey et al. ${ }^{12}$ e Almeida et al. ${ }^{7}$ mostraram que, além de preencher informações das DN, muitos profissionais não médicos auxiliam no preenchimento das Declarações de Óbito (DO) que é responsabilidade legal dos médicos ${ }^{13}$.

Com o objetivo de compreender os processos e os contextos envolvidos no registro e produção desses dados foi realizado um estudo empregando a abordagem de pesquisa qualitativa, na qual os entrevistados expressam suas ideias e se posicionam sobre o tema ${ }^{14}$, com enfermeiros e profissionais dos setores administrativos dos hospitais para estudar sua representação social sobre o preenchimento das DN e se, e como, auxiliam no preenchimento das DO fetais e neonatais, em hospitais SUS e não SUS.

\section{Método}

Este estudo foi realizado no âmbito da pesquisa "Avaliação da Qualidade da Informação sobre Mortalidade Perinatal no Município de São Paulo" que considerou os hospitais como unidades amostrais, sendo sorteados por amostragem estratificada proporcional ao número de óbitos perinatais em cada estabelecimento. As unidades são representativas da rede hospitalar não SUS (8) e das diferentes entidades mantenedoras que prestam serviço ao SUS (14), contemplando hospitais filantrópicos, estaduais, municipais e organizações sociais de saúde. Foram realizadas entrevistas em 16 hospitais (quatro não SUS e 12 SUS), em 2009.

Como critério de seleção dos entrevistados, os profissionais deveriam ter como rotina de trabalho o preenchimento das DN ou auxílio nas DO. Foi solicitado à coordenação dos hospitais que indicasse os profissionais. Foram entrevistados dois enfermeiros e cinco profissionais de setores administrativos em hospitais não SUS e seis enfermeiros e 11 profissionais de setores administrativos em hospitais do SUS, totalizando 24 entrevistas.

O roteiro de entrevista foi definido por perguntas abertas que buscaram contextualizar a rotina dos processos de trabalho e como o preenchimento das DN e DO se insere no cotidiano da prática profissional. O roteiro objetivava também captar a existência de possíveis dificuldades, a participação em treinamentos e as representações sociais sobre o SIM e o SINASC. 
Foi utilizada a técnica do Discurso do Sujeito Coletivo (DSC), procedimento metodológico de natureza qualiquantitativa, na qual a opinião é obtida por meio de questões abertas propiciando ao entrevistado produzir um depoimento discursivo. Cada questão gera um número variado de diferentes posicionamentos, ou seja, de distintos DSC que resultam de uma agregação de diferentes discursos ou extratos de discursos individuais que representam sentido semelhante ${ }^{15}$. O discurso de cada entrevistado pode conter uma ou mais ideias a respeito da questão estabelecida e, para o processo de análise, são atribuídas expressões chaves a cada ideia para que, então, seja possível agrupar as expressões chave de sentido semelhante em categorias de respostas. Com as categorias de ideias compartilhadas e seus respectivos discursos estabelecidos torna-se possível a análise qualitativa dos depoimentos de ideias compartilhadas em cada uma das questões ${ }^{15,16}$. Para análise dos resultados foi utilizado o software Qualiquantisoft ${ }^{17}$ e apresentados segundo tipologia do hospital SUS e não SUS

As representações sociais manifestas verbalmente são um conjunto de conceitos, frases e explicações originadas na vida diária durante o curso das comunicações sociais. São modalidades de conhecimento prático, orientadas para a comunicação e para a compreensão do contexto social, material e ideológico em que vivemos. Socialmente elaboradas e compartilhadas, contribuem para a construção de uma realidade comum possibilitando a comunicação entre os indivíduos. Portanto, são fenômenos sociais que devem ser compreendidos a partir do contexto de produção a que servem e das formas de comunicação onde circulam ${ }^{18}$.

A pesquisa foi previamente aprovada pelos Comitês de Ética em Pesquisa da Faculdade de Saúde Pública (USP), dos hospitais e da Secretaria Municipal de Saúde da prefeitura de São Paulo. Antes das entrevistas, foi lido e assinado o Termo de Consentimento Livre Esclarecido garantindo anonimato dos entrevistados e dos hospitais que participaram do estudo.

\section{Resultados}

Os resultados do presente trabalho trazem à luz distintas Representações Sociais sobre o tema enfocado: o preenchimento das DN e DO no contexto da dinâmica de trabalho de hospitais SUS e não SUS. Tais Representações Sociais, quando se utiliza o método do Discurso do Sujeito Coletivo para seu resgate, adquirem a forma de "depoimentos coletivos" (que, ao longo do trabalho, aparecem em "itálico"), construídos com estratos de diferentes depoimentos individuais que manifestam sentidos e percepções semelhante entre os respondentes.

Tais "depoimentos coletivos" revelam e descrevem o conteúdo manifesto das Representações Sociais que, junto com outros resultados empíricos, revelam uma das camadas de sentido relativa ao tema da produção das estatísticas vitais tais como elas se apresentam no cotidiano hospitalar. Estudos ulteriores que, ainda da perspectiva das Representações Sociais mas com uma abordagem mais sociológica, avancem em outras camadas de sentido buscando explorar porque tais Representações Sociais estão presentes, são por certo possíveis e mesmo necessários mas fogem do escopo do presente trabalho.

O Quadro 1 mostra o perfil dos profissionais entrevistados. Dos oito enfermeiros, uma metade trabalhava na obstetrícia e outra na pediatria ou UTI neonatal. Entre os outros profissionais indicados pela coordenação do hospital, observou-se grande diversidade dos setores de trabalho que variaram entre SAME (Serviço de Arquivo Médico e Estatística), setores administrativos, setor de internação entre outros. Foi solicitado que os entrevistados descrevessem suas rotinas de trabalho. Quatro enfermeiros relataram exercer atividade assistencial e os outros quatro, atividade administrativa. Entre os profissionais da área administrativa, oito relataram exercer apenas atividades administrativas e outros oito relataram que também faziam o registro de informações clínicas. Não foram observadas diferenças, nos hospitais SUS e não SUS, quanto às atividades dos enfermeiros e profissionais administrativos.

$\mathrm{Na}$ questão sobre a rotina do preenchimento da DN e DO, três enfermeiros de hospitais SUS descreveram que preenchem apenas parte da $\mathrm{DN}$, porque os dados cadastrais (informações individuais) são preenchidos pelo setor administrativo. Outros enfermeiros que trabalhavam em UTI neonatal/berçário informaram que recebiam, da sala de parto, as DN já preenchidas com os dados de identificação da mãe. Esta rotina visava facilitar o preenchimento das demais variáveis, pois no momento do parto a sala fica muito cheia e "tumultuada". Foi relatado pelos entrevistados que em alguns hospitais os dados eram preenchidos na sala de parto e em outros na maternidade/alojamento conjunto.

Em hospitais não SUS, duas enfermeiras preenchiam toda DN. Uma delas, que trabalhava na 
Quadro 1. Perfil dos profissionais entrevistados de acordo com tipologia do hospital, formação, cargo e setor de trabalho no hospital, Município de São Paulo, 2009.

\begin{tabular}{|c|c|c|c|c|}
\hline $\begin{array}{c}\text { SUS/ } \\
\text { não-SUS }\end{array}$ & Formação & Especialidade & Cargo & Setor \\
\hline \multicolumn{5}{|l|}{ Enfermeiros } \\
\hline $\begin{array}{l}\text { Não-SUS } \\
\text { Não-SUS } \\
\text { SUS } \\
\text { SUS } \\
\text { SUS } \\
\text { SUS } \\
\text { SUS } \\
\text { SUS }\end{array}$ & $\begin{array}{l}\text { Enfermagem } \\
\text { Enfermagem } \\
\text { Enfermagem } \\
\text { Enfermagem } \\
\text { Enfermagem } \\
\text { Enfermagem } \\
\text { Enfermagem } \\
\text { Enfermagem }\end{array}$ & $\begin{array}{c}\text { UTI infantil/Saúde Pública } \\
\text { Obstetrícia } \\
\text { Obstetrícia } \\
\text { Obstetrícia } \\
\text { Administração hospitalar } \\
\text { Obstetrícia } \\
- \\
\text { Auditoria }\end{array}$ & $\begin{array}{c}\text { Enfermeira líder } \\
\text { Enfermeira obstetra } \\
\text { Enfermeira obstetra } \\
\text { Enfermeira obstetra } \\
\text { Enfermeira } \\
\text { Encarregada técnica } \\
\text { Enfermeira } \\
\text { Enfermeira executiva }\end{array}$ & $\begin{array}{c}\text { UTI infantil } \\
\text { Maternidade/berçário/CO } \\
\text { Obstetrícia } \\
\text { Obstetrícia } \\
\text { Plantonista pediatria } \\
\text { CO } \\
\text { Pediatria } \\
\text { Alojamento conjunto/ } \\
\text { maternidade }\end{array}$ \\
\hline \multicolumn{5}{|c|}{ Outros profissionais } \\
\hline $\begin{array}{l}\text { Não-SUS } \\
\text { Não-SUS }\end{array}$ & $\begin{array}{c}\text { Ensino médio } \\
\text { Recursos } \\
\text { Humanos }\end{array}$ & $\begin{array}{c}\text { Curso Informática } \\
-\end{array}$ & $\begin{array}{l}\text { Técnico em informática } \\
\text { Supervisão atendimento }\end{array}$ & $\begin{array}{c}\text { Informática } \\
\text { Atendimento - internação }\end{array}$ \\
\hline $\begin{array}{l}\text { Não-SUS } \\
\text { Não-SUS } \\
\text { Não-SUS } \\
\text { SUS } \\
\text { SUS }\end{array}$ & $\begin{array}{c}\text { Ensino médio } \\
\text { Ensino médio } \\
\text { Administração } \\
\text { Enfermagem } \\
\text { Ciências } \\
\text { Contábeis }\end{array}$ & $\begin{array}{c}\text { Técnico laboratório industrial } \\
- \\
- \\
- \\
\text { Literatura }\end{array}$ & $\begin{array}{c}\text { Escriturária } \\
\text { Escriturária } \\
\text { Auxiliar administrativo } \\
\text { Agente de políticas públicas } \\
\text { Chefe de registro }\end{array}$ & $\begin{array}{c}\text { Maternidade } \\
\text { Maternidade/berçário } \\
\text { Internação } \\
\text { Internação } \\
\text { SAME/Registro }\end{array}$ \\
\hline $\begin{array}{l}\text { SUS } \\
\text { SUS } \\
\text { SUS } \\
\text { SUS } \\
\text { SUS } \\
\text { SUS } \\
\text { SUS } \\
\text { SUS } \\
\text { SUS }\end{array}$ & $\begin{array}{l}\text { Ensino médio } \\
\text { Ensino médio } \\
\text { Ensino médio } \\
\text { Ensino médio } \\
\text { Matemática } \\
\text { Ensino médio } \\
\text { Ensino médio } \\
\text { Ensino médio } \\
\text { Ensino médio }\end{array}$ & $\begin{array}{c}- \\
- \\
- \\
- \\
- \\
- \\
- \\
\text { Curso Informática } \\
\text { Auxiliar necropsia }\end{array}$ & $\begin{array}{l}\text { Oficial administrativo } \\
\text { Agente de políticas públicas } \\
\text { Auxiliar administrativo } \\
\text { Auxiliar administrativo } \\
\text { Auxiliar administrativo } \\
\text { Chefe de sessão } \\
\text { Auxiliar administrativo } \\
\text { Auxiliar administrativo } \\
\text { Auxiliar necropsia }\end{array}$ & $\begin{array}{c}\text { Registro geral } \\
\text { Alojamento conjunto } \\
\text { Internação } \\
\text { Internação } \\
\text { SAME } \\
\text { Divisão de arquivo médico } \\
\text { Maternidade } \\
\text { Obstetrícia/ginecologia } \\
\text { Necrotério }\end{array}$ \\
\hline
\end{tabular}

UTI neonatal, relatou que fica sob sua responsabilidade o preenchimento das DN de recém-nascidos que precisavam de cuidados imediatos. Outra enfermeira relatou que a direção do hospital estabeleceu que o preenchimento do documento deveria ficar a cargo de poucas pessoas, visando garantir informações mais claras e precisas, tal responsabilidade foi atribuída as enfermeiras.

Em relação ao preenchimento da DO fetal e neonatal foi perguntado se os médicos recebiam auxílio para o preenchimento. No relato das enfermeiras foram observadas três situações: uma não sabia responder; duas afirmaram que o médico não recebia auxílio (hospitais SUS). Entre os relatos de que o médico recebe auxílio, uma enfermeira indicou que os dados de identificação eram preenchidos pelo SAME (hospital não SUS) e quatro enfermeiras (três de hospitais SUS e uma não SUS) relataram que auxiliam os médicos com informações dos prontuários, observadas na sala de parto ou baseadas em informações das DN.

Entre os relatos dos profissionais administrativos 12 indicaram que as informações das DO relativas à identificação das mães não são preenchidas pelos médicos e sim por profissionais da admissão, internação ou SAME e que essas informações são consideradas como dados cadastrais. Essa rotina é justificada pela necessidade de apresentação de documentos por parte dos pacientes, para que os nomes sejam preenchidos correta- 
mente, assim como a confirmação de endereço e CEP. Tais dados dificilmente seriam coletados pelos médicos, devido à sua rotina de trabalho.

As ideias centrais relativas às dificuldades de preenchimento surgem em relatos diferentes entre os profissionais administrativos e enfermeiros, principalmente quando referentes a campos específicos da DN. Em dois hospitais SUS e um não SUS foram descritas dificuldades distintas em relação ao preenchimento do nome da mãe, relatadas em duas situações:

Hospital não SUS - A dificuldade que a gente tem é o nome da mãe que muitas vezes quando ela entra no hospital ela mostra o $R G$ de solteira, e não fala que é casada e quem tá fazendo a matrícula também não pergunta. Então toda a ficha dela é feita sobre aquele nome, e eu preencho a declaração de nascido vivo conforme está no sistema, então quando essa declaração chega pra ela [mãe], ela verifica o nome e fala que é casada. Eu arrumo na frente e atrás da declaração.

Hospital SUS - Às vezes elas falam o nome e às vezes não é aquele nome, tem que estar também pegando o RG delas, tem muito caso social de moradora de rua, pacientes que vivem, como que eu posso falar pra você, dá o nome e é outro.

Em um hospital não SUS foi relatada dificuldade no preenchimento da escolaridade materna, pois na maior parte das vezes essa informação não é dada em anos de estudo e pode ser ainda fornecida por parentes da paciente:

Hospital não SUS - No caso da mãe, [o acompanhante] vai falar: 'não sei, eu acho que ela estudou até o ensino médio, ah não sei, eu acho que ela tem a faculdade tal', e você tem que ter uma noção do tempo, dos anos que ela estudou para poder tá fazendo o preenchimento. Seria mais fácil no caso da declaração se nós pudéssemos escrever de próprio punho a escolaridade do paciente, do cliente.

Foram relatadas dificuldades no preenchimento do endereço, tanto por enfermeiras como pelo pessoal administrativo. No hospital não SUS a dificuldade se refere à informação do CEP da residência, mas a busca no prontuário resolve, pois essa informação está sempre presente. Nos hospitais SUS houve o relato de que as mães ou parentes têm dificuldade em fornecer o endereço correto. Em um hospital foi relatado o caso de mães bolivianas que têm medo de fornecer o endereço.

Hospital SUS - Muitas vezes elas vêm com o endereço que é diferente daquele que ela reside, elas dão o endereço ou então quem vem acompanhando elas dá endereço e quando você vai confirmar no leito é outro endereço, eu não moro mais aí, esse é o endereço da minha mãe, é o endereço da minha tia, e onde estou morando eu moro há pouco tempo então eu não sei, então é melhor recolher das próprias pacientes. Não sei se pelo grau de escolaridade das pessoas, é difícil você conseguir a informação correta da própria paciente ou pelo fato do filho estar com ela ali, não sei se elas ficam meio desorientadas, meio com receio de preencher alguma coisa, de responder.

A informação sobre o estado civil foi mencionada como problemática na rede SUS e não SUS. Os relatos indicam a dificuldade em explicar para a mãe a diferença entre união estável e casamento civil. Muitas vezes a mãe que tem um companheiro, mas não é casada legalmente, não quer que seja preenchido como solteira. O campo referente à ocupação foi mencionado por uma enfermeira de hospital SUS. Segundo a entrevistada, a mãe adolescente que só estuda não pode ser classificada como desempregada, mas ao mesmo tempo não possui ocupação.

Foram descritas dificuldades em relação à raça/cor dos recém-nascidos, principalmente quando os pais são de raça/cor diferentes. Entretanto, as enfermeiras e profissionais relatam que essa dificuldade tem diminuído após orientação da equipe do SINASC de que esse dado deve ser autorreferido. Apenas enfermeiros e profissionais de hospitais SUS relataram dificuldades de preenchimento em relação ao histórico materno e malformações congênitas. Uma enfermeira relatou que precisa ajudar no preenchimento, porque as escriturárias que são responsáveis pela DN não têm o conhecimento específico necessário para esses campos:

Hospital SUS - Como é rotina do nosso serviço esse preenchimento é com a escriturária, a gente acaba tendo dificuldade sim, porque elas não têm o mesmo entendimento que o enfermeiro para saber, às vezes na maternidade a gente tem que auxiliar a escriturária nos dados, algumas perguntas que são mais complexas que elas não sabem preencher. Elas sentem mais dificuldade, às vezes é quando a idade gestacional que elas nunca sabem se é prematuro, também é paridade, se ela tem filho vivo ou morto, se esse morto é natimorto ou se é considerado como abortamento, elas sempre fazem confusão, então a gente sempre tem que estar lá confirmando e direcionando elas no preenchimento. Elas não são fixas, por causa que elas tem o problema delas das folgas no setor, às vezes acaba vindo outras escriturárias que não tem habilidade nenhuma com DNV.

Um profissional do setor administrativo de hospital SUS descreveu que geralmente os médicos se esquecem de preencher o item malformação congênita, então é necessário devolver os 
documentos para que este campo seja preenchido corretamente.

Hospital SUS - Digamos, tem o campo 34 se tem má formação ou não. É o pediatra que tem que estar preenchendo no centro obstétrico, geralmente eles esquecem e nós temos que estar indo atrás dele tem que estar perguntando.

As dificuldades mencionadas pelas enfermeiras foram relativas à definição da malformação:

Hospital SUS - A gente escreve o que os pediatras conseguem definir na hora, alguma coisa muito evidente, um pé torto congênito ou um dedo extranumerário, só que às vezes, uma coisa que eles não decidiram na hora, eles vão pesquisar que muitas vezes são os residentes que pegam os bebês, eles não sabem definir, só que eu não posso esperar essa definição para colocar na DNV, ai eu coloco o que eles colocaram na ficha. Isso que gera mais dúvidas das anomalias, mas o hospital nos deu o curso, foi lá na secretaria, se você tiver dúvida eles deixaram telefone tudo, de repente a gente tem uma dúvida daquela anomalia a gente pode até fotografar e mandar pra lá, eles. Mas, se por exemplo, eles não sabem se o bebê tem uma síndrome de Down, que eles vão ainda pesquisar, se não colocaram eu não vou por também.

Nos hospitais SUS houve também o relato de dificuldades do preenchimento de informações sobre características maternas e da gestação, como por exemplo, sobre a assistência pré-natal, pois as mães não levam ou esquecem o cartão de pré-natal onde seria possível obter as informações necessárias:

Hospital SUS - Os campos sobre paridade, número de filhos, consultas. Elas esquecem a carteirinha de pré-natal ou às vezes elas não trazem porque é um lugar fora da região, então elas tem medo que a gente transfira ou que não aceite, então elas nem trazem. Como é que você vai escrever o número de consultas? Eu escrevo o que? O que ela refere, põem ignorado? Não sei também. Eu acabo anotando o que os obstetras anotam, eles perguntam para ela, então acaba sendo assim.

Foram feitas perguntas sobre o treinamento para preenchimento dos documentos, para verificar se os profissionais receberam instruções e se auxiliaram no preenchimento das declarações. Uma enfermeira de hospital SUS referiu que trabalha com recém-nascidos há mais de 20 anos e aprendeu o preenchimento da DN na prática, conforme foi sendo incorporada no dia a dia de trabalho. Cinco enfermeiras relataram que receberam orientações do supervisor ou colegas de trabalho que já haviam participado de treinamentos ou tinham a rotina de preenchimento.
Enfermeiras: Hospital SUS - Eu só fui orientada como preencher, mas não um curso formal. A orientação foi dada pela minha chefe. Porque ela que vai nessas reuniões e passa pra gente, mas eu acho que como é tudo muito específico acho que precisa ter um curso mesmo, de algumas horas para discutir cada ponto, porque é muito complicado isso. E às vezes, eu acho assim, que por falta de informação cada uma acaba preenchendo o que acha melhor, o que acha correto.

Outros profissionais: Hospital SUS - Eu aprendi no dia a dia. com ajuda do pessoal que já sabia, passou ó, preenche, então foi assim sem curso sem nada. Então se você vai para determinado setor alguém te treina para assumir aquilo ali. Agora capacitação, propriamente dita, não.

A participação em treinamento e capacitação promovida pela Secretaria Municipal de Saúde São Paulo (SMS/SP) foi relatada com maior frequência pelos profissionais administrativos do que pelas enfermeiras. Todas as respostas indicam a importância dos treinamentos para esclarecimento de dúvidas e que, após a capacitação, os profissionais se sentem mais seguros para preencher os documentos.

Hospital SUS - A declaração de nascido vivo eu tive [treinamento], fui no SINASC teve uma reunião onde eles estavam explicando novamente como preencher. Um dos campos que eu recebi muito treinamento foi sobre endereço, ter o CEP certinho, tem que ter o numero, o distrito corretamente, porque tudo isso vai pela internet. E o outro ponto do nascido vivo era raça/cor que não era preenchido, eles pedem para a gente preencher, no caso assim éa auto declaração da mãe, a gente pergunta para a mãe, a mãe que declara. O último que teve foi sobre anomalias congênitas, foi bom porque tinham algumas dúvidas sobre as anomalias.

Hospital não SUS - Lá no SINASC foi muito bom, eles esclarecem bastante as dúvidas. Depois de lá que foi, que assim que eu vim primeiro pro setor, depois que eu fui lá, então a gente se sente mais segura na hora de preencher.

Os profissionais do administrativo que auxiliam no preenchimento da DO relataram que receberam instruções de outros profissionais do setor, enquanto que para DN participaram de treinamentos fornecidos pela equipe do SINASC.

Hospital SUS - Logo que fui admitida aqui no setor a minha chefia anterior que passou, que me orientou quanto ao preenchimento das DO. Aqui, tinha uma pessoa que ela já fazia isso, aî você pega o documento na prática né, a gente procura preencher todos os campos necessários porque depois eles também têm uma certa dificuldade, às vezes eu 
deixo de preencher alguma coisa, não preencher o sexo, não por a cútis da pessoa, aí o rapaz da funerária liga, qual é a cor? Principalmente estrangeiro, japonês, né, porque pra mim, Mitsú é nome feminino, só que na realidade é masculino. Agora das DNV eu participo frequentemente das reuniões porque sempre há mudança de sistemas, antes era por disquete a gente mandava a relação mensal por esse disquete, dava a maior confusão, eles vinham instalar, né, programas novos agora tudo é através da internet, está ótimo. Então são essas mudanças que está participando sempre.

Com objetivo de identificar a representação social que os enfermeiros e profissionais administrativos do hospital tinham a respeito do uso das informações registradas nas DN e DO foi perguntado: Para que servem as informações das declarações de nascido vivo e de óbito que você preenche? Como assim? Em relação ao uso das informações, quatro enfermeiras indicaram que as informações das DN e DO possuem finalidade estatística e epidemiológica e quatro disseram que, além deste uso, também servem para registro de nascimento e de óbito no cartório.

Hospital SUS - Essa declaração de nascidos vivos ela serve para que essa pessoa seja registrada no cartório, registro de nascimento de que ela nasceu e a localidade, onde ela nasceu, a data é importante para que a pessoa seja registrada e reconhecida no País. A importância dela não só para a criança ter um registro, ser um cidadão.

Hospital não SUS - ...e também eu acho que é um Censo do Ministério da Saúde para saber o que está acontecendo, como essas crianças estão nascendo, e se essas mulheres estão fazendo pré-natal, não estão, as informações pessoais, acho que é pra tudo isso, então são importantes, são informações importantes e que precisa ter uma uniformidade no preenchimento disso.

Cinco profissionais do administrativo relataram que a finalidade das informações e as declarações servem apenas para fins de registro e de documentação legal para a família.

Hospital SUS - É para que saia correto para a família não ter problemas futuros. Elas tem uma importância muito grande porque é o registro da criança, então é o começo de tudo, então assim, a gente tem que ter muita responsabilidade porque qualquer errinho lá a pessoa leva para a vida toda na verdade. E a de óbito se você não faz o preenchimento aí não tem dado que a pessoa realmente faleceu, que ela morreu, você tem que ter um documento de comprovação.

Entretanto, a maior parte dos profissionais considera que as informações são importantes para uso epidemiológico e estatístico.
Hospital SUS e não SUS - Bom, é um controle muito grande aí do Ministério da Saúde, nós vemos, estamos em constantes reuniões com o SINASC porque é uma informação do Brasil todo de nascimentos, de controle de certidões de nascidos vivos por regiões, então é um controle muito grande deles, quais os tipos de mães, por exemplo em tal bairro, porque está tendo mais nascimentos em tal lugar e não no outro, então eles avaliam as malformações também que são informadas nas DN, então eles avaliam também a parte social também. E os das DO também é importante pelo controle no Ministério da Saúde também, o total da população também e os diagnósticos acho que para pesquisa da saúde mesmo, quais os motivos de morte, mas da declaração de óbito já não sei muito. No treinamento do SINASC eu vi que cada informação é importante, como lá me explicaram que é da DN que tiram a quantidade de vacinas por região, o nosso então é uma informação assim importante, que é passada adiante. Então todas as informações são assim estudadas.

\section{Discussão}

Os hospitais podem ser considerados unidades produtoras das informações do SIM e SINASC e, por esta razão, as entrevistas ocorreram nesse locus. Neste estudo foi abordada a percepção do profissional de saúde sobre o SIM e o SINASC e ainda, como os profissionais percebem a importância das atividades que realizam nesse processo. Os profissionais de saúde, em conformidade com a teoria das Representações Sociais ${ }^{18}$, percebem e atuam em seu universo de ação (aqui, os hospitais), usando categorias de conhecimento ou esquemas sociocognitivos coletivamente compartilhados.

A coleta de dados e a operação dos sistemas de informação SIM e SINASC são de responsabilidade das secretarias municipais de saúde ${ }^{19} \mathrm{e}$ existem diferenças nos fluxos dos documentos e da operação entre os dois, no município de São Paulo. As DO preenchidas nos hospitais são entregues aos familiares, que devem se dirigir ao Serviço Funerário Municipal que irá proceder o enterramento e encaminhar uma cópia da DO ao Cartório de Registro Civil e outra ao Programa de Aprimoramento das Informações de Mortalidade no Município de São Paulo (PROAIM/SMS/ SP), que é responsável pela digitação dos dados.

As DN são preenchidas e digitadas pelos hospitais onde ocorreu o nascimento e o banco de dados é enviado a SMS/SP ${ }^{20}$. Uma cópia da DN é fornecida à família para a obtenção da Certidão 
de Nascimento junto aos Cartórios de Registro Civil. Desse modo, o hospital não preenche apenas o documento básico do SINASC, como também é uma unidade de alimentação do sistema. Essas diferenças irão se refletir nas representações que os profissionais possuem destes documentos e na qualidade da informação de óbitos e nascidos vivos.

Vários estudos têm mostrado que a completitude das variáveis das DN é elevada. Almeida et al. ${ }^{21}$, mostraram que a ausência de registro de informações no SINASC é inferior a 5\%, para a maioria das variáveis no MSP, Costa e Frias ${ }^{22}$ também encontraram resultados semelhantes em estudo realizado em Pernambuco. Entretanto, estudos $^{21}$ têm mostrado que completitude das informações registradas nas declarações de óbitos perinatais é bem menor.

Tanto nos hospitais SUS como não SUS não se verificou um padrão relativo ao profissional responsável pelo preenchimento das DN, confirmando os resultados encontrados por Mishima et al. ${ }^{10}$. Observou-se que os enfermeiros e o pessoal administrativo dos hospitais preenchem a DN. Em alguns hospitais o profissional administrativo é responsável pelo preenchimento dos dados cadastrais e as enfermeiras pelas demais informações e em outros são responsáveis pelo preenchimento de toda DN. Nos hospitais SUS foi relatado que o preenchimento das DN anteriormente era de responsabilidade do SAME, mas foi repassada às enfermeiras, para que seu preenchimento ocorresse na sala de parto.

Com relação à DN os discursos sobre as dificuldades encontradas no seu preenchimento indicam a existência de semelhanças e diferenças entre as categorias profissionais e tipologia de hospitais (SUS e não SUS). Os profissionais de hospitais SUS mencionaram mais dificuldades do que os profissionais de hospitais não SUS. Essas dificuldades expressam particularidades do nível de formação, do tipo de ambiente de trabalho particular a cada sujeito que participou da pesquisa e do perfil de usuários SUS e não SUS.

Em hospitais SUS foram relatadas dificuldades na obtenção de algumas variáveis como o número de consultas de pré-natal, números de filhos vivos e mortos, pois muitas vezes estas não estavam registradas nos prontuários, indicando a fragmentação tanto da atenção à gestante e ao parto, como a falta de integração entre atenção primária e os hospitais. Foram relatadas dificuldades para a obtenção da variável estado civil da mãe em hospitais SUS e não SUS. Os discursos indicam que as mães têm dificuldade de diferen- ciar união consensual e união legal. Outra variável que também apresentou dificuldade para sua obtenção é a escolaridade materna, porém há um esforço dos profissionais em obter informações corretas, o que sugere o comprometimento destes com a qualidade da captação dessas informações na DN.

Também foram descritas dificuldades em relação ao endereço da mãe, o que se deve, em parte, ao momento em que esta informação é obtida (ingresso) e em parte reflete as condições de vida dos usuários. Em um hospital não SUS a maior dificuldade era o CEP, mas o profissional conseguia contornar facilmente este problema, pois esses dados constavam e eram bem preenchidos no prontuário. Enquanto que nos hospitais SUS muitas vezes os endereços fornecidos no momento da internação não eram os mesmos quando confirmados pelas mães. Esse fato mostra a importância do registro e da checagem dos dados no momento do cadastro do paciente, como apontado por Arts et al. ${ }^{5}$.

Entre as dificuldades relativas à variável presença de malformações congênitas houve a menção de ausência de registro pelos médicos nos prontuários, dificuldades de entendimento do registro quando este está presente e a própria dificuldade de identificar a presença de malformações. Guerra et al. ${ }^{11}$ indicam que o profissional do setor administrativo responsável por essas informações nem sempre tem familiaridade com os termos médicos registrados no prontuário, o que pode dificultar sua obtenção. Geremias et al. ${ }^{23} \mathrm{e}$ Guerra et al. ${ }^{11}$ indicaram que as DN subestimam a presença de malformações congênitas, ocorrendo principalmente o registro das malformações que são aparentes no momento do nascimento.

Apesar de orientações contidas nos treinamentos sobre a DN indicarem que a raça/cor deve ser autorreferida pela mãe, verificou-se que ainda persistem dúvidas sobre esta variável. Com objetivo de aprimorar esta informação a nova versão da DN substituiu esse quesito pela raça/ cor da mãe?

Observou-se também que, em vários hospitais, os profissionais do setor administrativo realizam a digitação e a checagem de dados de identificação dos pacientes da DN indicando que os hospitais exercem claramente o papel de unidade produtora da informação na operação do SINASC. O conhecimento das representações sociais, viabilizado neste trabalho pelo uso da técnica do Discurso do Sujeito Coletivo, revela-se como um instrumento para as intervenções (treinamen- 
tos, capacitações, reciclagens, etc.) visando o aperfeiçoamento profissional na medida em que aproximando as intervenções do conhecimento manifestado pelos profissionais nas suas Representações Sociais, consegue-se um contato mais eficiente (não apenas do ponto de vista cognitivo mas também do afetivo, pela via da identificação) dos agentes da intervenção com os profissionais sobre os quais pretende-se intervir.

Observou-se que os treinamentos fornecidos pela SMS-SP sobre o SINASC são considerados fundamentais no dia a dia dos profissionais que preenchem as DN, tanto para esclarecimento de dúvidas quanto para que conheçam a importância das informações que produzem. Além dos constantes treinamentos, a SMS/SP criou, em 2010, o Selo SINASC que fornece um certificado de qualidade baseado em critérios como: cobertura de eventos, pontualidade da digitação dos dados, completitude das informações e controle do uso dos formulários ${ }^{24}$. Além disso, a partir de 2011 as dúvidas quanto ao preenchimento das DN podem ser resolvidas por meio eletrônico e são divulgadas informações do sistema e resultado anuais do selo SINASC. Referidas medidas de incentivo e interação com as instâncias produtoras da informação resultam no aprimoramento do sistema. O envolvimento e o comprometimento dos profissionais com o sistema asseguram informações mais fidedignas, conforme afirma Arts et al. ${ }^{5}$.

Apesar da definição legal de que o médico é o responsável pelas informações da $\mathrm{DO}^{13,19}$, muitas vezes os profissionais de setores administrativos preenchem as informações de identificação individual, as variáveis sobre características maternas e o histórico da gestação. Como esta responsabilidade não é oficialmente atribuída a estes profissionais, eles não recebem treinamento específico para esclarecimento de dúvidas e orientações a respeito do preenchimento da DO. Por outro lado, a ausência de treinamento reforça a representação que esses profissionais expressaram nos seus discursos sobre o seu papel secundário no SIM.

As entrevistas revelaram que os profissionais conhecem e reconhecem a utilidade das informações registradas nas DN, com base nos treinamentos fornecidos pela equipe do SINASC. Consideram que as informações de óbito têm a mesma finalidade, mas não têm certeza e muita clareza quanto à utilização dos dados.

Segundo Jodelet ${ }^{18}$, a construção do conhecimento dos processos de trabalho acontece de forma distinta. Para o preenchimento da DN esse processo se dá por meio de treinamentos específicos, enquanto que para a DO esse conhecimento é adquirido por meio da partilha entre os profissionais no dia a dia de trabalho. Essas duas formas, ambas apoiadas em representações sociais (a serem obtidas pela via de pesquisas empíricas com uso de metodologia qualitativa), quando bem manejadas, podem, cada uma a sua maneira, contribuir positivamente para o uso cada vez mais adequado da informação na prática da assistência à saúde.

\section{Conclusão}

A participação efetiva dos hospitais na operação do SINASC na coleta, digitação e verificação das informações, desempenhando a função de unidade produtora de informação é diferentemente do que ocorre no SIM. Além disso, os constantes treinamentos do SINASC contribuem para a qualidade dos dados.

Outro aspecto que pode contribuir para ausência de registro de dados (exceto causas de morte) nas DO perinatais refere-se ao fato de que os outros profissionais que preenchem parte desses documentos, não são os responsáveis legais (médicos), o que pode levar a não se perceberem como parte integrante do sistema. Em relação ao SINASC os profissionais e os enfermeiros se reconhecem como parte integrante do processo de produção da informação. Os discursos indicam que a atividade está incorporada na rotina do trabalho; há comprometimento na busca de soluções, quando se deparam com dificuldades de preenchimento; há valorização de se sentirem acompanhados por uma instância superior do sistema e sentem que o treinamento é um espaço de encontro para retorno e compreensão das finalidades e usos das informações que produzem. A participação dos profissionais de enfermagem se mostrou fundamental para boa qualidade dos registros das informações e aumenta o comprometimento, assegurando informações mais fidedignas.

\section{Colaboradores}

D Schoeps, MF Almeida, PR Raspantini, HMD Novaes, ZP Silva e F Lefevre participaram igualmente de todas as etapas de elaboração do artigo. 


\section{Referências}

1. Zeitlin J, Wildman K, Bréart G, Alexander S. Selecting an indicator set for monitoring and evaluating perinatal health in Europe: criteria, methods and results from the PERISTAT project. Eur J Obstet Gynecol Reprod Biol 2003; 111(Supl.):S5-S14.

2. Almeida MF, Alencar GP, Novaes HMD, Ortiz LP. Sistemas de informação e mortalidade perinatal: conceitos e condições de uso em estudos epidemiológicos. Rev. bras. epidemiol. 2006; 9(1):56-68.

3. Kirby RS. The quality of data reported on birth certificates. Am J Public Health 1997; 87(2):a301301.

4. Lima CRA, Schhramm JMA, Coeli CM, Silva MEM. Revisão das dimensões de qualidade dos dados e métodos aplicados na avaliação dos sistemas de informação em saúde. Cad Saude Publica 2009; 25(10): 2095-2109.

5. Arts DG, De Keizer NF, SchefferGJ. Defining and improving data quality in medical registries: a literature review, case study, and generic framework. $J$ Am Med Inform Assoc 2002; 9(6):600-611.

6. Mello Jorge MHP, Laurenti R, Gotlieb SLD. Análise da qualidade das estatísticas vitais brasileiras: a experiência de implantação do SIM e do SINASC. Cien Saude Colet 2007; 12(3):643-654.

7. Almeida MF, Alencar GP, Schoeps D, Minuci EG, Silva ZP, Ortiz LP, Novaes MDH, Alencar AP, Raspantini PR, Santos PC. Qualidade das informações registradas nas declarações de óbito fetal em São Paulo, SP. Cad Saude Publica 2011; 4(5):845-853.

8. Solomon DJ, Henry RC, Hogan JG, Van Amburg GH, Taylor J. Evaluation and implementation of public health registries. Public Health Rep 1991; 106(2):141-150.

9. Brasil. Ministério da Saúde (MS). Secretaria de Vigilância em Saúde. Manual de Instruções para o preenchimento da Declaração de Nascido Vivo. Brasília (DF): MS, SVS; 2009.

10. Mishima FC, Scochi CGS, Ferro MAR, Lima RAG, Costa IAR. Declaração de Nascido Vivo: Análise do seu preenchimento no Município de Ribeirão Preto, São Paulo, Brasil. Cad Saude Publica 1999; 15(2):387-395.

11. Guerra FAR, Lerena JC, Gama SGN, Cunha CB, Theme MMF. Confiabilidade das informações das declarações de nascido vivo com registro de defeitos congênitos no Município do Rio de Janeiro, Brasil, 2004. Cad Saude Publica 2008; 24(2):438-446.

12. Niobey FML, Cascão AM, Duchiade MP, Sabroza PC. Qualidade do preenchimento de atestados de óbitos de menores de um ano na região metropolitana do Rio de Janeiro. Rev Saude Publica 1990; 24(4):311-318.

13. Brasil. Resolução CFM no $1.601 / 00$, de 9 de agosto de 2000 - Regulamenta a responsabilidade médica no fornecimento da Declaração de Óbito. Diário Oficial da União 2000; 18 Ago.
14. Spink MJP. O conceito de representação social na abordagem psicossocial. Cad Saude Publica 1993; 9(3):300-308.

15. Lefevre F, Lefevre AMC. O discurso do sujeito coletivo: um novo enfoque em pesquisa (desdobramentos). Caxias do Sul: EDUCS; 2003.

16. Lefevre F, Lefevre AMC. O sujeito coletivo que fala. Interface Comun Saúde Educ 2006; 10(20):517-524

17. SPi-Sales \& Paschoal informática. Elaborado com base na teoria do DSC. [acessado 2013 mar 29]. Disponível em: www.spi.com.br

18. Jodelet D, organizadora. As representações Sociais. Rio de Janeiro: Ed. UERJ; 2001.

19. Brasil. Ministério da saúde. Secretaria de Vigilância em Saúde. Portaria no 116 , de 11 de fevereiro de 2009. Regulamenta a coleta de dados, fluxo e periodicidade de envio das informações sobre óbitos e nascidos vivos para os Sistemas de Informações em Saúde - SIM e Sinasc. Diário Oficial da União 2009; 12 fev.

20. São Paulo (Município). Portaria no 325, de 15 de maio de 2004. Regulamenta a coleta de dados e organização do fluxo do SINASC no município de São Paulo. Diário Oficial da Cidade de São Paulo 2004; 16 maio.

21. Almeida MF, Alencar GP, França Junior I, Novaes HMD, Siqueira AAF, Schoeps D, Rodrigues LC, Campbell O. Validade das informações das declarações de nascidos vivos com base em estudo de caso-controle. Cad Saude Publica 2006; 22(3):643-652.

22. Costa JMBS, Frias PG. Avaliação da completitude das variáveis da Declaração de Nascido Vivo de residentes em Pernambuco, Brasil, 1996 a 2005. Cad Saude Publica 2009; 25(3):613-624.

23. Geremias AL, Almeida MF, Flores LPO. Avaliação das declarações de nascido vivo como fonte de informação sobre defeitos congênitos. Rev. bras. epidemiol. 2009; 12(1):60-68.

24. Romero DE, Cunha CB. Avaliação da qualidade das variáveis sócio-econômicas e demográficas dos óbitos de crianças menores de um ano registrados no Sistema de Informações sobre Mortalidade do Brasil (1996/2001). Cad Saude Publica 2006; 22(3):673-681.

Artigo apresentado em 02/10/2012

Aprovado em 16/11/2012

Versão final apresentada em 04/12/2012 